\title{
Editorial comment on "An International Urogynecological Association (IUGA)/International Continence Society (ICS) Joint Report on the Terminology for Female Pelvic Floor Dysfunction"
}

\author{
Peter K. Sand • Jacques Corcos
}

Received: 17 October 2009 /Accepted: 19 October 2009/Published online: 25 November 2009

(C) The International Urogynecological Association 2009

The article by Haylen et al., "An International Urogynecological Association (IUGA) / International Continence Society (ICS) Joint Report on the Terminology for Female Pelvic Floor Dysfunction" in the current issues of International Urogynecology Journal and Neurourology \& Urodynamics represents a historic milestone in the history of two great organizations dedicated to the care of incontinence and pelvic floor dysfunction. Through the persistent efforts and tireless work of Bernie Haylen and the wisdom and openmindedness of Dirk DeRidder, these respective heads of their organizations' standardization committees recognized that the collaborative work of these two international organizations was the best way to approach refining the terminology for female pelvic floor dysfunction. In doing so, they set a precedent and a model for subsequent collaborative publications between these two organizations that can only serve to improve the knowledge and communication of physicians, nurses, physiotherapists and all the other clinicians and scientists who work diligently to improve the lives of female patients. IUGA and ICS have organized successful joint annual meetings and we wish such success for this and other future collaborative efforts.

This is the first time that female-specific terminology has been developed. It represents a significant change from the

The article discussed here can be found at doi:10.1007/s00192-0090976-9.

P. K. Sand $(\bowtie)$

IUGA, Urogynecology, NorthShore University HealthSystem,

Evanston, IL, USA

e-mail: peterksand@gmail.com

J. Corcos

ICS, Urology, Jewish General Hospital,

Montreal, Quebec, Canada
"First Report on the Standardisation of Terminology of Lower Urinary Tract Function" which was first published in the British Journal of Urology [1] in 1976. Many of the original qualifications of terminology in the First Report have been addressed over the past 33 years, but not in such a comprehensive fashion for female pelvic floor dysfunction as in this joint report by Haylen et al. This report combines the input of members of the Standardization and Terminology Committees of two international organizations, the International Urogynecological Association (IUGA) and the International Continence Society (ICS), assisted at intervals by many external referees. Appropriate core clinical categories and a subclassification were developed to give an alphanumeric coding to each definition. An extensive process of 15 rounds of internal and external review was developed to exhaustively examine each definition, with decision-making by collective opinion (consensus) followed by external review by the members of both organizations on their websites.

The original Standardisation Committee was composed of some of the greatest minds in dysfunction of the lower urinary tract function, and revising their work and the subsequent revision by Abrams et al. [2] in 2002 was very difficult. It was hoped by the combined committees that integration of this new terminology for females would be easier to understand for the practicing clinician.

For this report on female terminology to be relevant, it must be useful and become integrated into the daily lexicon of healthcare providers of women. Therefore, it is important that all of the members of the IUGA and the ICS adopt these terms and recognize the source by qualifying all scientific presentations with the quote that "Methods, definitions and units conform to the standards recommended by the International Urogynecological Association (IUGA) / International Continence Society (ICS) Joint Report on the Terminology for Female Pelvic Floor Dysfunction, except 
where specifically noted". It is observed that this is less commonly done now in the literature than in decades past and perhaps should be part of the review process for journals in the field, as are many other standards. We encourage you to review and adopt these terms in your daily work and to feel free to bring forward any suggestions that you may have for revision of this report in the future. Despite the exhaustive review that went into the preparation of this report, there is always room for critique and further revision.

\section{References}

1. Bates P, Bradley WE, Glen E, Melchior H, Rowan D, Sterling A, Hald T (1976) First report on the standardization of terminology of lower urinary tract function. Br J Urol 48:39-42

2. Abrams P, Cardozo L, Fall M, Griffiths D, Rosier P, Ulmsten U, van Kerrebroeck P, Victor A, Wein A (2002) The standardization of terminology of lower urinary tract function: report from the standardisation sub-committee of the international continence society. Neurourol Urodynam 21:167-78 